\title{
Por UMA INVENÇÃo ÉTICA PARA OS DiReitos Humanos
}

\author{
Cecília Maria Bouças Coimbra* \\ Lilia Ferreira Lobo** \\ Maria Livia do Nascimento***
}

\section{RESUMO}

Através do referencial teórico da Filosofia da Diferença buscamos problematizar alguns conceitos como os de civilização, barbárie, direitos, humano, evolução e progresso, dentre outros. Para tanto, historicizamos a gênese dos Direitos Humanos no contexto da Declaração de 1948, em plena Guerra Fria, e no Brasil, com a emergência dos novos movimentos sociais a partir de 1975. Esses acontecimentos históricos, apesar de sua importância, produziram efeitos naturalizadores e essencialistas, esvaziando e capturando, muitas vezes, a luta pelos Direitos Humanos. Ao afirmarmos um direito e uma humanidade positivados enquanto processos, trazemos a discussão de uma ética da imanência.

Palavras-chaves: direitos; humano; ética; processos de subjetivação.

\section{Abstract}

FOR AN ETHICAL INVENTION FOR HUMAN RigHTS

By the means of the Philosophy of Difference as a theoretical reference, we seek to place in discussion concepts such as civilization, barbary, rights, human, evolution and progress, among others. Therefore, we historicize the genesis of Human Rights, in the context of the 1948 Declaration, during the Cold War, and, in Brazil, with the emergence of the new social movements after 1975. These historical happenings, besides having their importance, have produced effects of essentialism and naturalism, emptying and capturing, many times, the

* Professora do Departamento de Psicologia da Universidade Federal Fluminense (UFF).

** Professora do Departamento de Psicologia da Universidade Federal Fluminense (UFF).

*** Professora do Departamento de Psicologia da Universidade Federal Fluminense (UFF). 
struggle for Human Rights. When positively affirming the right and humanity as processes, we raise the discussion of an ethics of immanence.

Keywords: rights; human; ethics; subject-affirming processes.

Quando se comemoram os 60 anos da Declaração Universal dos Direitos Humanos de 1948, torna-se importante problematizar alguns fundamentos históricos, filosóficos e políticos das produçōes que vêm sendo naturalizadas no cotidiano das lutas por esses direitos.

Em primeiro lugar, é comum considerá-los como conquistas da civilização moderna contra a barbárie do mundo antigo, como frutos de uma evolução em direção ao progresso do chamado gênero humano. Entendemos, portanto, ser importante colocar em análise esses termos que, de tão evidentes e repetidos, passam a ser percebidos como verdades tácitas, cabais, inquestionáveis, a-históricas, atribuindo-lhes determinadas essências. Vamos priorizar aqui alguns desses termos, tais como barbárie, civilização, evolução, progresso, direitos e humano, embora outros pudessem ser apresentados.

Segundo Foucault (1979), a história clássica e oficial que nos tem sido ensinada é concebida como uma marcha contínua dos acontecimentos históricos em direção a uma teleologia que representaria o progresso, a civilização ou, mesmo, o fim da história. Assim, estágios antecedentes nos levariam obrigatoriamente a um futuro de perfeição ou à aproximação gradativa do que deve ser a perfeição. $\mathrm{O}$ mundo burguês nos faz acreditar nas qualidades da civilização moderna, desqualificando tudo o que o precedeu - o que se pode chamar de etnocentrismo histórico. Ou seja, o nosso presente no mundo ocidental - a partir de certos parâmetros valorativos - julga, hierarquizando, as diferentes histórias dos povos, inclusive a nossa própria história. José Carlos Rodrigues (1999) confirma:

Qualificar de moderno é elogiar e despertar orgulho. Mais ainda é adjetivar de pós-moderno. Referir-se, porém, a algo ou alguém de medieval é quase como utilizar uma categoria de acusação, uma vez que esse tempo passou a ser considerado como uma época de bárbaros, como Idade das Trevas, como a noite de mil anos (Rodrigues, 1999: 21).

Portanto, o que chamamos de barbárie seria um corpo estranho à civilização, uma espécie de herança maldita que teima em persistir, uma oposição, uma dicotomia e não um paradoxo produzido pelo nosso mundo dito civilizado. Tal dicotomia entre civilização e barbárie é um produto do nosso tempo, visto que nunca se utilizou tanto esses dois conceitos, justamente em um momento em que 
a segurança torna-se a palavra de ordem. Com ela está o controle, a punição, a tutela, embora uma de suas funções seja, justamente, a de dissimulá-los e de naturalizá-los.

Foucault ([1975-1976] 2002) caracteriza este momento da sociedade disciplinar, em especial a partir do final do século XVIII, como o "fazer viver e deixar morrer", quando cada vez mais necessitamos que muitos morram para que outros possam viver. Por isso, precisamos jogar para fora do nosso tempo e atribuir ao "passado bárbaro" o horror que hoje vivemos - os genocídios, os extermínios, os doentes negligenciados, as torturas - como se toda uma tecnologia que nos apregoa o bem-estar ou, na linguagem neoliberal, a qualidade de vida e a tal autoestima não estivesse também a serviço deste biopoder racista que diz servir à vida à custa da mortificação da maioria da população do planeta. Entendemos, assim, que civilização e barbárie não se opõem, fazendo parte do funcionamento da sociedade capitalista. Tal lógica, que nega os binarismos, pode ser encontrada também nos escritos de Marx ([1867] 1968), quando em O capital, por exemplo, explica o mecanismo por meio do qual a acumulação de capital produz, ao mesmo tempo, a riqueza e aquilo que é caracterizado como seu contrário, a miséria, imprescindível à existência de mais e mais riqueza.

\section{Historicizando os Direitos Humanos}

A burguesia iluminista precisava derrotar a nobreza e o clero, impor-lhes limites, e ao mesmo tempo precisava conter as massas pobres que sonhavam com uma república livre, igualitária e fraterna. $\mathrm{O}$ poder precisava atualizar-se, não punir menos, mas punir melhor, com a eficácia do utilitarismo econômico (Batista, 2008a: 1).

Os ideais da Revolução Francesa - igualdade, liberdade e fraternidade -, palavras de ordem da burguesia em ascensão, tornaram-se, a partir do fim do século XVIII, os fundamentos dos chamados direitos humanos. Produzidos pelo capitalismo como um dado natural, tornaram-se, portanto, sinônimos de direitos inalienáveis da essência do que é ser homem. Tem-se, então, um determinado "rosto" para os direitos humanos desde a primeira grande declaração produzida no âmbito da luta realizada pela burguesia contra a aristocracia francesa, em 1789, até a mais recente declaração, a de 1948, quando, após a Segunda Grande Guerra Mundial, foi criada a Organização das Naçôes Unidas (ONU) em pleno período da chamada "guerra fria". Estão presentes nessas duas grandes declarações - que se tornaram marcos para a história da humanidade - os direitos, em realidade reservados e garantidos para as elites. Um dos mais defendidos 
e, em nosso mundo, considerado sagrado é o direito à propriedade, garantido apenas para os que a possuem. Os direitos humanos, portanto, têm apontado quais são esses direitos e para quem eles devem ser concedidos. Ou seja, se tomados em sua perspectiva histórica, tanto o humano como os direitos são construçôes das práticas sociais em determinados momentos, que produzem continuamente esses objetos, subjetividades e saberes sobre eles. Pensando como Foucault, entendemos que seu método

consiste [...] em compreender que as coisas não passam das objetivaçôes de práticas determinadas, cujas determinações devem ser expostas à luz, já que a consciência não as concebe [...]. Tudo gira em volta desse paradoxo, que é a tese central de Foucault e a mais original: o que é feito, o objeto, se explica pelo que foi o fazer em cada momento da história; enganamo-nos quando pensamos que o fazer, a prática, se explica a partir do que é feito (Veyne, 1982: 162-164).

Deleuze (1992) afirma que os direitos humanos - desde sua gênese - têm servido para levar aos subalternizados a ilusão de participação, de que as elites preocupam-se com o seu bem-estar, de que o humanismo dentro do capitalismo é uma realidade e, com isso, confirma-se o artigo primeiro da Declaração de 1948: "todos os homens nascem livres e iguais em dignidade e direitos". Entretanto, sempre estiveram fora desses direitos à vida e à dignidade os segmentos pauperizados e percebidos como "marginais": os "deficientes" de todos os tipos, os "desviantes", os miseráveis, dentre muitos outros. A estes, efetivamente, os direitos, assim como a dimensão humana, sempre foram - e continuam sendo - negados, pois tais parcelas foram produzidas para serem vistas como "subalternas" ou como nãopertencentes ao gênero humano. Não há dúvida, portanto, que esses direitos proclamados pelas diferentes revoluçôes burguesas, contidos nas mais variadas declarações - tenham construído subjetividades que definem para quais humanos os direitos devem se dirigir. Os marginalizados de toda ordem nunca fizeram parte desse grupo que, ao longo dos séculos XIX, XX e XXI, tiveram e continuam tendo sua humanidade e seus direitos garantidos. Ou seja, foram e continuam sendo defendidos certos tipos de direitos, dentro de certos modelos, que terão que estar e caber dentro de certos territórios bem marcados e delimitados e dentro de certos parâmetros que não poderão ser ultrapassados.

Percebemos aqui como as diferentes práticas sociais, em diferentes momentos da história, vão produzindo diferentes "rostos", diferentes "fisionomias"; portanto, diferentes objetos, diferentes entendimentos do que são direitos e do que é humano. Estes não têm uma evolução ou origem primeira, mas emergem, em certos momentos, de maneiras bem peculiares. 
Em vez de pensar os direitos como essência universal do homem, poderíamos, por meio de outras construçôes, garantir e afirmá-los como diferentes modos de sensibilidade, diferentes modos de viver, existir, pensar, perceber, sentir; enfim, diferentes jeitos de estar e existir no mundo. Entretanto, essas afirmações da vida em suas potências são ainda vistas como estando fora dos tradicionais direitos humanos, porque não estão presentes nos modelos condizentes com a "essência” do que é direito e do que é humano. Rachar a expressão direitos humanos, tão naturalmente utilizada, e mesmo banalizada ${ }^{1}$ no contemporâneo, possibilitou-nos pensar na diferenciada emergência histórica desses dois objetos: direitos e humano. Da mesma forma que o direito é construído como sendo um atributo universal, uma determinada concepção de homem também vem sendo produzida historicamente, desde o século XVIII. Foucault (1979) nos alerta que:

A história ensina também a rir das solenidades da origem [...] gosta-se de acreditar que as coisas em seu início se encontravam em estado de perfeição; que elas saíram brilhantes das mãos do criador, ou na luz sem sombra da primeira manhã [...]. Mas o começo histórico é baixo (Foucault, 1979: 18).

O surgimento de uma concepção do humano e da universalização dos direitos não se deu da forma tão grandiosa e afirmativa como nos querem fazer acreditar as revoluções burguesas e suas declaraçōes. Naquele mesmo período, no século XVIII, foi necessário dar visibilidade científica ao chamado indivíduo perigoso, através do saber médico e da reforma das práticas de punição, para que uma nova forma de ordenação social pudesse se manter: a normalização das populaçōes.

O corpo social deixa de ser simples metáfora jurídico-política [...] para surgir como uma realidade biológica e um campo de intervenção médica. [...] A psiquiatria, na virada entre os séculos XVIII e XIX, conseguiu sua autonomia e se revestiu de tanto prestígio pelo fato de ter podido se inscrever no âmbito de uma medicina concebida como uma reação aos perigos inerentes ao corpo social (Foucault, [1994] 2006: 9).

Foi, portanto, pela forma negativa do anormal, do perigo social, da monstruosidade, que se construiu o universo da norma como aquilo que seria próprio do humano:

O normal, enquanto a-normal, é posterior à definição do normal, é a negação do normal, é a negação lógica deste. No entanto, é a anterioridade histórica do futuro anormal que provoca uma intenção normativa. O normal é o efeito 
obtido pela execução do projeto normativo, é a norma manifestada no fato. Do ponto de vista do fato há, portanto, uma relação de exclusão entre o normal e o anormal. Esta negação, porém, está subordinada à operação de negação, à correção reclamada pela anormalidade. Não há, portanto, nenhum paradoxo em dizer que o anormal, que logicamente é o segundo, é existencialmente o primeiro (Canguilhem, 1978: 216).

E o que constituiria a norma senão um conjunto de regras morais que impõem sua existência pela possibilidade de sua infração? Eis o que nos aproxima do pensamento de Alain Badiou (1999), quando ele nos diz que se a experiência do inumano é clara, a do humano é obscura, tendo em vista que é "o humano que delimita o ponto de aplicação dos direitos do homem” (Badiou, 1999: 47-48), sendo o homem uma dupla negação, aquele que não é inumano. Ou seja, nos acostumamos a pensar sempre a partir da negação e do território da falta.

Queremos, entretanto, afirmar aqui um direito e uma humanidade positivada enquanto processos imanentes, não definidos, não dados e não garantidos necessariamente pelas leis - que vêm se tornando cada vez menos jurídicas e cada vez mais normativas -, mas que, por isso mesmo, precisam afirmar a vida em toda a sua potência de criação. A desnaturalização dos conceitos de direitos e de humano implica em um desafio permanente para todos nós no sentido de inventar novas práticas e novos mundos. Marcamos aqui, portanto, uma afirmação da processualidade dos direitos como conquista datada historicamente e do humano como permanente criação de si e de modos de viver. Estranhamos e problematizamos, assim, a crença em um conceito abstrato de direito e de homem. Afirmamos, de forma radical, que é a partir das experiências de cada homem na coletividade, na imanência das práticas e das lutas no tempo histórico, que uma humanidade vai se definindo e construindo. Nesse sentido, Barros e Passos (2005) afirmam que "não havendo uma imagem definitiva e ideal d'O Homem só nos resta aceitar a tarefa sempre inconclusa de reinvenção de nossa humanidade, o que não se pode fazer sem o trabalho também constante da produção de outros modos de vida, de novas práticas" (Barros \& Passos, 2005: 570).

Da mesma forma, Deleuze (1992) nos potencializa problematizando todo e qualquer conceito:

Não buscaríamos origem mesmo perdidas ou rasuradas, mas pegaríamos as coisas onde elas crescem, pelo menos rachar as coisas, rachar as palavras. Não buscaríamos o eterno, ainda que fosse a eternidade do tempo, mas a formação 
do novo, a emergência ou o que Foucault chamou de atualidade (Deleuze, 1992: 109).

Reafirmamos que, se não entendemos os direitos e o humano como objetos naturais, obedecendo a determinados modelos que lhes seriam inerentes, podemos produzir outros direitos humanos: não mais universais, absolutos, contínuos e em constante evolução, mas a afirmação de direitos locais, descontínuos, fragmentários, processuais, em constante movimento e devir, múltiplos como as forças que os atravessam e os constituem. Enfim, a afirmação da jurisprudência no lugar da lei, como nos propóe Deleuze (2008).

No Brasil, a luta pelos direitos humanos emerge com força nos movimentos contra a ditadura militar. Surgem com os chamados novos movimentos sociais que se efetivam ainda na segunda metade dos anos 1970, com práticas que começaram a rechaçar os movimentos tradicionalmente instituídos e que politizaram o cotidiano nos locais de trabalho e moradia, inventando novas formas de fazer política. Vieram quando "novos personagens entraram em cena” (Sader, 1988), quando emergiram "novos sujeitos políticos" que, no cotidiano, lutavam por melhores condições de vida, trabalho, salário, moradia, alimentação, educação, saúde e pela democratização da sociedade. Esses movimentos começaram a existir com os próprios "estilhaços" que resultaram das derrotas impostas aos movimentos sociais com o golpe de 1964 e com o AI5, em 1968. Seus "sobreviventes", ao resgatar criticamente as várias experiências de oposição nos anos de 1960 e 1970, fizeram emergir nos bairros e, logo a seguir, nas fábricas "novas políticas" que substituíram as tradicionalmente utilizadas. Sobretudo, das crises da Igreja, das esquerdas e do sindicalismo - que a ditadura acirrou e aprofundou - surgiu uma série de movimentos sociais produzindo novos caminhos. Estes, por sua vez, forjaram práticas ligadas à teologia da libertação, repensaram certas leituras do marxismo, a oposição armada à ditadura e o movimento sindical. Emergiram, desses novos movimentos sociais, dessas novas práticas, outros rostos, outras fisionomias para os direitos humanos. Vários grupos surgiram como importantes trincheiras contra as violências cometidas e, ainda hoje, persistem na disposição de afirmar e apontar para as lutas em prol dos direitos daqueles cujas existências continuam sendo marginalizadas.

Entretanto, apesar da potência desses movimentos, que possibilitaram formas de expressão contrapostas ao fechamento ditatorial, as lógicas de poder e as racionalidades de Estado não foram modificadas, sequer atingidas. As lutas que pretendiam alcançar a igualdade e a justiça social acreditavam - e ainda acreditam - piamente que isto só poderia acontecer pela tomada e apropriação do aparelho 
do Estado. Mudanças só seriam operadas a partir da utilização das mesmas racionalidades que, segundo Agamben (2004), constituem a máquina estatal moderna: as hierarquias instituídas pela representação e, paradoxalmente, pelo Estado de exceção. Estaremos longe, portanto, de uma nova ética afirmativa dos direitos enquanto não enfrentarmos o risco das revoluções, não mais das macrorevoluçôes, sempre fadadas ao fracasso, e sim das rupturas das revoluções moleculares de nossas práticas cotidianas de poder.

\section{Estado Penal E Estado de EXCEÇÃo}

O estado de exceção, hoje, atingiu exatamente seu máximo desdobramento planetário. $\mathrm{O}$ aspecto normativo do direito pode ser, assim, impunemente eliminado e contestado por uma violência governamental que, ao ignorar no âmbito externo o direito internacional e produzir no âmbito interno um estado de exceção permanente pretende, no entanto, ainda aplicar o direito (Aganbem, 2004: 131).

Apesar das chamadas boas intenções presentes na defesa dos direitos humanos e na importância que a ela vem sendo atribuída, sua concepção e práticas hegemônicas, oficiais ou não, são dominadas pelo "problema do Mal e pela figura da vítima” (Badiou, 1999: 47). Daí a produção de palavras de ordem ancoradas na negação e na falta, tais como "socorrer as vítimas e assegurar o direito dos homens contra o sofrimento" (Badiou, 1999: 47). Tais princípios têm fundamentado e garantido tanto a constituição das leis e o exagero de sua multiplicação, quanto as chamadas intervenções humanitárias. Estas vêm se afirmando como mercadoria de consumo que se vende a bons preços no mercado capitalístico de direitos humanos. Tem sido, também, dentre várias outras, uma das mais insidiosas capturas às quais os movimentos sociais na atualidade vêm se submetendo. Trata-se, portanto, de um conjunto de movimentos punitivos que buscam a maximização do Estado penal e o fortalecimento do Estado de exceção.

Quanto maior a conflitividade social decorrente da devastação promovida pelo capital, maior deve ser a legitimidade da pena. O que vai articular essa nova economia política é a constituição de uma cultura punitiva, talvez só conhecida na inquisição e no nazismo (Batista, 2008a: 3).

Diante dessas constatações, podemos nos perguntar: por que a prisão venceu? Comparando-se com a velocidade das novas tecnologias (biotecnologia, 
robótica, dentre outras), há a permanência/fortalecimento/expansão de uma das mais antigas "instituições de seqüestro" (Foucault, [1973] 2005) que permanece sendo aperfeiçoada pela cultura punitiva, tornando-se cada vez mais robusta em suas práticas de seqüestro: a prisão. Ainda segundo Foucault ([1973] 2005), esta não seria somente uma resposta à infração, mas sobretudo trata-se de corrigir o perigo de certos comportamentos, até mesmo das intençôes, das más disposições, das tendências para o crime. Portanto, a prisão não teria emergido do campo do Direito ou das teorias jurídicas, mas das próprias práticas de controle social dispersas e produzidas por diferentes comunidades. Os famosos exemplos trazidos por Foucault das lettres-de-cachée, na França, e dos quakers, na Inglaterra - dispositivos de controle e vigilância criados por demanda da população (no caso da França), ou pela própria população (no caso da Inglaterra) ${ }^{2}-$, serviram mais tarde de modelos para a institucionalização da prisão e da polícia.

Frente à legislação penal da sociedade de soberania, a prisão e a polícia aparecem como medidas de escape dos horrores do suplício (Foucault, [1975] 1986). O fato de terem emergido do controle do próprio grupo, e não dos teóricos juristas da época, lhes dá força de continuidade e rapidamente são capturadas pelo novo aparelho de Estado, tornando-se o dispositivo triunfante de punição no capitalismo.

No momento em que a prisão passa a ser o instrumento principal de castigo torna-se necessária a construção de uma máquina jurídica e judiciária forte, configurada nos procedimentos dos tribunais, de seus especialistas em políticas penais e em comportamentos e virtualidades humanas.

Com a complexidade crescente dessas práticas, assistimos hoje a diversas intermediações jurídicas presentes nas mais diferentes relações, caracterizando um cotidiano juridiciarizado ${ }^{3}$. Assistimos, também, à constante busca de puniçõos e de penas mais duras e severas como garantia de manutenção da ordem social.

Lá se foram os anos em que desejávamos as rupturas. Hoje as subjetividades estão mergulhadas no tempo das reformas, ou seja, da permanência aperfeiçoada das mesmas instituições, consideradas em si necessárias, definitivas, imprescindíveis ao progresso da humanidade. Hoje se criou toda uma máquina jurídica: da hipo-suficiência, da vulnerabilidade, da vitimização, das deficiências. Estas seriam compensadas pela máquina estatal e judiciária como um poder de soberania de soberanos vitalícios que são os juízes, promotores nos tribunais, os chamados na contemporaneidade operadores de direito e do Ministério Público - para manter o equilíbrio instável do paradoxo capitalístico, capital e miséria. Para isso é preciso criar o mínimo, que seria o mínimo necessário ao consumo, que sempre produzirá o balanceamento entre a falta e o gozo, entre o pedido e o favor. Nunca 
o máximo, a completude do inacabamento, a razão de ser da própria liberdade e da vida. Sempre o mínimo: o salário mínimo para "proteger" o trabalhador, a bolsa mínima para "reparar" o dano da miséria; ou seja, os diferentes programas assistenciais compensatórios. Para haver reparação, recuperação, reabilitação, restabelecimento é preciso instaurar o dano e produzir a vulnerabilidade, assim como os especialistas da insuficiência que acreditam em todas essas "ilusões re" Daí o medo da insegurança, não mais do que pode acontecer no futuro, mas no presente, o medo que nos acossa a cada momento, obrigando-nos a buscar abrigo na esperança de dias melhores, aplacando a potência de agir e de inventar, através da obediência e do conformismo.

O aprofundamento dessa cultura punitiva vai trazer as páginas policiais para o centro da questão política, todos os problemas serão trazidos para o penal e irão engrossar o coro da demanda de mais poder punitivo [...]. Somos hoje muito menos críticos contra o Estado policial do que éramos na saída do ciclo militar. A truculência contra os pobres constitui-se um fim em si mesma, não precisa nem mais explicar-se através da eficiência. O importante é punir (Batista, 2008a: 4).

Essa cultura vem se fortalecendo após o 11 de setembro. A crença no policiamento ostensivo, na baixa da idade penal, na prisão perpétua, na pena de morte "sem dor", na tortura light como mal menor necessário", nos interrogatórios mais humanos, nos extermínios massivos, principalmente nos territórios perigosos da pobreza. Todas essas práticas iniciadas nos Estados Unidos desde os anos de 1970, com a política de tolerância zero e o encarceramento em massa ${ }^{6}$, ao globalizar-se prenunciam o Estado Penal que irá inaugurar o terceiro milênio. Hoje vivemos subjetividades cujo eixo gira única e exclusivamente em torno da garantia de nossa segurança privada. Por isso, clamamos pela humanização do Estado de exceção, pela reforma de seus dispositivos policiais e por mais leis, que em realidade nos tutelam e nos constrangem. Aí está a certeza da nossa segurança - a existência das leis que devem ser cumpridas.

A transcendência da lei historicamente nos persegue, talvez por isso confundamos o legal com o legítimo, a moral com a ética. O legado filosófico de Sócrates, que, apesar de inocente, aceitou sua condenação à morte para confirmar a superioridade da lei da cidade sobre os homens, confere até hoje uma essência negativa ao humano, quando atribui uma natureza a-histórica e transcendente à dicotomia entre o Bem e o Mal, tornando, mais do que nunca, as sanções da lei a principal necessidade de segurança para a manutenção da ordem social. 


\section{Precisamos de uma inVEnÇão Ética para os Direitos Humanos}

Eis, pois, o que é a Ética, isto é, uma tipologia dos modos de existência imanente, substitui a moral, a qual relaciona sempre a existência a valores transcendentes. A Moral é o julgamento de Deus, o sistema do Julgamento. Mas a Ética desarticula o sistema do julgamento. A oposição dos valores (Bem/Mal) é substituída pela diferença qualitativa dos modos de existência (bom/mau) (Deleuze, 2002: 29).

Será que precisamos realmente buscar transcendência para as práticas em nosso cotidiano? Estaríamos perdidos sem a referência de uma transcendência qualquer, uma entidade separada de nós, a palavra de ordem de um universal, como a aceitação do Bem e a rejeição do Mal, fundamentos necessários à regulação dos comportamentos humanos? Sabemos que o Mal - considerado por Platão como simulacro, sempre percebido como risco de degradação - acaba sendo construído historicamente como coisa em si, absoluta e universal. Ou seja, dentro da visão platônica somente o Bem habitaria o mundo perfeito e ideal das essências ${ }^{7}$. Esta é uma das questões éticas da maior importância. Quase tudo que o nosso mundo vem construindo como referente à transcendência só serviu de fundamento de verdade para a lei e a moral, nunca para uma reflexão crítica dirigida ao que elas produzem como culpa e expiação. Sempre o dever ser negativo e prescritivo no lugar de um devir positivo de invenção. A dificuldade extrema não se coloca apenas em "evitar o espetáculo do Mal" e atacá-lo, afastando-o pela ameaça da punição também extrema. A dificuldade maior está em como podemos nos tornar sujeitos de práticas éticas em nosso dia-a-dia sem nos reduzirmos aos códigos e restrições existentes em qualquer sociedade. Como discernir entre atitudes passivas de submissão, subserviência e constrangimento das atitudes ativas das práticas de liberdade? Como, em meio às relações de poder que, muitas vezes, nos oprimem e tornam esse mundo insuportável, estabelecer relações de cuidado de si e dos outros (Foucault, [1982-1983] 2008), sem esperar recompensa ou castigo? Um devir ético da imanência não se processa apenas nas lutas contra forças negativas do mundo: o abuso de poder, a menorização e desqualificação do outro, todo tipo de racismo que nos atravessa liquida a vida. Sem dúvida, tais lutas são absolutamente necessárias, direitos precisam ser constantemente conquistados e não simplesmente "resgatados" como algo perdido que sempre esteve lá, em algum lugar, esperando para ser encontrado. É isto que constrói a figura nefanda da vítima, tão cara ao opressor.

Por isso, entendemos que os 60 anos da Declaração Universal dos Direitos Humanos não é algo apenas para ser lembrado e celebrado. Pode ser um instru- 
mento ativo de transformação das práticas que ainda hoje, em nome dos direitos humanos, trazem a marca essencialista. Diferentemente, essa Declaração deve ser utilizada como uma estratégia de transvaloração do direito e do humano. Ou seja, não se trata de resgatá-la, mas de afirmar essa conquista como algo que sempre requer as forças ativas das lutas agônicas que travamos conosco mesmos, para que possamos nos construir como criadores de possibilidades, como nos ensina Badiou (1999), numa atividade constante do desassossego que constitui a maravilha do viver. Portanto, mais uma vez, nos aliamos a Deleuze (1992) quando nos diz:

Acreditar no mundo é o que nos falta: nós perdemos completamente o mundo, nos desapossaram dele. Acreditar no mundo significa principalmente suscitar acontecimentos, mesmo pequenos, que escapem ao controle, ou engendrar novos espaços-tempos, mesmo de superfície ou volumes reduzidos [...]. É no nível de cada tentativa que se avaliam a capacidade de resistência ou, ao contrário, a submissão a um controle. Necessita-se ao mesmo tempo de criação e povo (Deleuze, 1992: 218).

\section{REFERÊNCIAS BIBLIOGRÁFICAS}

Agamben, G. (2004). Estado de exceção. São Paulo: Boitempo.

Aussaresses, P. (2008). Je n'ai pas tout dit: ultimes révélations au Service de la France. Paris: Editions du Rocher.

Badiou, A. (1999). Conferências de Alain Badiou no Brasil. Belo Horizonte: Autêntica.

Barros, R. \& Passos, E. (2005). A humanização como dimensão pública das políticas de saúde. Ciência e Saúde Coletiva, 10, 3, 561-571.

Batista, V. M. (2008a). O preocupante porvir. Rio de Janeiro: Instituto Carioca de Criminologia, mimeo. . (2008b). Adeus às ilusões "re”. mimeo.

Canguilhem, G. (1978). O normal e o patológico. Rio de Janeiro: Forense-universitária. Deleuze, G. (1992). Conversaçôes. Rio de Janeiro: Editora 34. . (2002). Espinosa: filosofia prática. São Paulo: Escuta. . (2008). O Abecedário Gilles Deleuze. Disponível em: <www.oestrangeiro.net/ index2.php?option=com_content\&do_pdf=1\&id=67>. Acessado em 25/07/2008. Foucault, M. (1973). A verdade e as formas jurídicas. Rio de Janeiro: Nau, 2005. (1975). Vigiar e punir. Petrópolis: Vozes, 1986.

- (1975-1976). Em defesa da sociedade. São Paulo: Martins Fontes, 2002. . (1979). Microfísica do poder. Rio de Janeiro: Graal. 
. (1982-1983). Le gouvernement de soi et des autres: Cours au Collège de France.

Paris: Seuil/Gallimard, 2008.

. (1994). Ditos e escritos. Rio de Janeiro: Forense Universitária, 2006.

Fuganti, L. A. (1990). Saúde, desejo e pensamento. Em Lancetti, A. (Org.). Saúde e loucura 2 (pp. 18-82). São Paulo: HUCITEC.

Marx, K. (1867). O Capital. Rio de Janeiro: Civilização Brasileira, 1968.

Rodrigues, J. C. (1999). O corpo na história. Rio de Janeiro: Editora Fiocruz.

Sader, E. (1988). Quando novos personagens entram em cena. Rio de Janeiro: Paz e Terra.

Veyne, P. M. (1982). Foucault revoluciona a história. Em Como se escreve a história (pp. 150-181). Brasília: UnB.

Wacquant, L. (2001a). Os condenados da cidade: estudo sobre marginalidade avançada. Rio de Janeiro: Revan/Fase.

. (2001b). Prisóes da miséria. Rio de Janeiro: Zahar.

. (2001c). Punir os pobres: a nova gestão da miséria nos Estados Unidos. Rio de Janeiro: Freitas Bastos/Instituto Carioca de Criminologia.

\section{NoTAS}

1 Vide diferentes reportagens realizadas nos dois últimos anos pela grande imprensa brasileira sobre a luta contra a impunidade, em especial a série de reportagens do jornal $O$ Globo "Impunidade: o Brasil vive o crime sem castigo", de 2007.

2 As lettre-de-cachée eram cartas dirigidas ao rei da França (séculos XVII e XVIII) por figuras da população que demandavam a prisão de indivíduos considerados de conduta vergonhosa para a comunidade. O encarceramento ocorria sem julgamento e sem definição do prazo de permanência. De acordo com Foucault ([1973] 2005), tal prática não pertencia ao campo do Direito no sistema penal desses séculos. Os quakers organizavam sua própria polícia, que tinha a função de vigilância e auto-defesa contra os enforcamentos que em geral incidiam sobre os membros de comunidades religiosas dissidentes do anglicanismo.

3 Utilizamos tal neologismo para afirmar que tanto o aparelho jurídico quanto o judiciário são faces da mesma moeda, funcionando articuladamente.

4 Termo utilizado por Vera Maluguti Batista (2008b) em seu artigo "Adeus às ilusões 're".

5 Podemos aqui apontar dois momentos dessa defesa de práticas de tortura justificadas em função da vida. Um primeiro, na voz do General Paul Aussaresses (2008), ex-agente do serviço secreto da França, veterano das guerras do Vietnã e da Argélia, que colaborou com o regime militar brasileiro, ensinando aos oficiais técnicas de tortura e de combate à guerrilha e que também atuou no golpe contra Salvador Allende, no Chile. Em seu livro Je n'ai pas tout dit: ultimes révélations au Service de la France, ele justifica a tortura como necessária para 
"evitar a morte de inocentes". Uma segunda defesa da tortura aparece em atos que vêm sendo aprovados no Congresso Norte-americano.

6 Sobre o tema consultar Wacquant (2001a, 2001b, 2001c).

7 Para Platão o mundo perfeito e ideal é a única realidade. O mundo sensível, aquele que habitamos, é o mundo das cópias imperfeitas, das ilusões. Sobre o assunto consultar Fuganti (1990) e Deleuze (2002).

Recebido em 23 de março de 2008 Aceito para publicação em 29 de agosto de 2008 